\title{
Cultura popular en la primera etapa de la resistencia peronista (1955-1958)
}

Ernesto José Salas

$\mathrm{E}$

1 presente trabajo tiene por objeto destacar algunos valores de la cultura popular de Argentina en el periodo posterior al golpe militar de 1955 que derrocó al gobierno de Perón. Fueron estos valores los que, después del exilio del presidente y del desmembramiento del Partido Peronista y sus organizaciones, se consolidaron como identidad de la mayoría de la clase trabajadora, motivada por las acciones políticas de protesta de sus grupos y sindicatos, acciones que dieron lugar a lo que se denominó la "re. sistencia peronista".

Algunos historiadores se han ocupado recientemente de dotar de sentido a las categorías "lo popular" y la "cultura popular". Stuart Hall, particularmente, propone que "el principio estructurador de 'lo popular' [...] son las tensiones y oposiciones entre lo que pertenece al dominio central de la cultura de elite o dominante y la cultura de la 'periferia' ", evitando así cata. logar a la popular como el contenido cristalizado existente de una cultura pura del pueblo original y colocándola en el espacio más complejo de la lucha entre las clases por la hegemonía. En sus palabras: "Lo que importa no son los objetos intrínsecos o fijados históricamente de la cultura, sino el estado de juego en las relaciones culturales $[\ldots]^{n}{ }^{1}$ Ubicando entonces el término en la dinámica histórica y en las relaciones de fuerza por la hegemonía, adquiere importancia definir los momen-

\footnotetext{
${ }^{1}$ Hall, "Notas", 1984.
} 
tos de "resistencia" y los momentos de "contención" de la cultura popular por la cultura dominante y los momentos ubicados entre estos dos polos de la contradicción. Dice Godelier que "cualquier práctica es simultáneamente económica [material] y simbólica; a la vez que actuamos a través de ella nos la representamos atribuyéndole un significado" ${ }^{2}$ Este sentido amplio de la cultura ha sido cuestionado por su misma amplitud. Dado que hemos ubi. cado en términos de dinámica histórica a la cultura popular, insistimosen que ésta no puede ser determinada por valores intrínsecos que le serían propios sino en la lucha por la hegemonía.

Podría argüirse, de todas maneras, que el aditamento de "popular" oscurece más que aclara la categoría de cultura, ¿por qué no hablar de cultura obrera, por ejemplo? Vuelvo a Stuart Hall:

[...] no hay una relación de uno a uno entre una clase y una determinada forma o práctica cultural [...]. Las culturas de clase tienden a cruzarse y a coincidir en el mismo campo de lucha. El término "popular" indica esta relación un tanto desplazada entre la cultura y las clases. ${ }^{3}$

De todas maneras, pocas veces se han analizado aspectos de la cultura popular en documentos elaborados por organismos de base: comisiones gremiales, sociedades de fomento de los barrios, clubes, asociaciones de ayuda voluntaria, etc. Ni tampoco los significados que el pueblo atribuye a las acciones de estos organismos: pa-

${ }^{2}$ Ctt. en García Canclini, Ideología, 1988.

3 Hall, "Notas", 1984. ros, movilizaciones callejeras, organización gremial en las fábricas, luchas en los barrios por mejoras, etc. Esto es producto de haber atendido poco a los aspectos de la oralidad y de la transmisión oral como espacio por donde es posible captar la virtual resignificación de los mensajes de los medios masivos de comunicación, o su aceptación acrítica.

Es necesario aclarar que, en este trabajo, no están contemplados todos los aspectos de la llamada cultura popular del periodo, sino solamente algunos de aquellos que, a mi juicio, configuran el nudo central de una etapa de resistencia cultural, y que están ligados al significado atribuido a las acciones de oposición de los sectores populares, particularmente de la clase obrera. Muchas veces no me fue posible determinar con precisión el origen de estos valores, pero fue más sencillo ubicar los canales de transmisión de. los mismos.

Mi hipótesis es que en el periodo tratado existe una resistencia cultural construida de manera compleja y que la transmisión de estos significados resistentes se hacía mediante una red de estructuras informales de organización y comunicación formada por los "comandos de la resistencia", las "comisiones internas de fábrica" y las organizaciones juveniles políticas. Estas organizaciones informales ocupaban espacios seguros: los barrios, los clubes, las fábricas, las casas, las cárceles, los estadios de futbol, etc. El resultado es la conformación de significados complejos que se han hallado en el presente investigado, en tanto que son resabios de la experiencia previa, y que 
constituyen una conciencia de clase no siempre homogénea ni determinada sólo por las relaciones materiales entre las clases. Involucran tanto consenso como oposición, aun cuando la suma de experiencias configura una etapa de alta homogeneidad política y el reforzamiento de una identidad reactiva a los modelos materiales y culturales de la clase dominante.

\section{LA "REVOLUCIÓN LIBERTADORA"}

El periodo inmediatamente posterior al derrocamiento de Perón en 1955 ha sido caracterizado como una etapa restauradora. En efecto, el conglomerado de fuerzas políticas y sociales que participó o aplaudió el golpe militar esta. ba hegemonizado por los sectores dela gran burguesía agraria que, en 1943 , habían sido desplazados del Estado. Dos hechos marcan el contenido de la nueva política: en primer lugar, el consenso que el golpe obtuvo de la burguesía y una parte importante de los sectores medios estaba basado en la común caracterización del peronismo como antidemocrático y autoritario; en segundo lugar, el reclamo de que el golpe debía limitar drásticamente el poder de los sindicatos y reducir las presiones que, a diario, ejercían los obreros sobre los empresarios amparados por la amplia legislación social peronista. Ambas aspiraciones fueron difundidas por los medios de comunicación en los meses posteriores al golpe.

Con estos presupuestos, ese golpe llamado "Revolución Libertadora" se aprestó, en los primeros meses de 1956, a desarticular las bases de sus- tentación del derrotado peronismo. ${ }^{4}$ Una serie de decretos marcaron la ofensiva político-sindical del gobierno de facto. En lo político, disolvió el Partido Peronista y prohibió su reorganización bajo cualquier sigla que pretendiera ocupar su lugar; los cargos militares que Perón ostentaba le fueron suprimidos; la Fundación que dirigiera Eva Perón fue disuelta y la residencia que ambos habían ocupado -el palacio Unzué en la avenida Libertador- fue demolida. El cadáver de Eva Perón fue sustraído secretamente y sa. cado del país sin que se conociera su paradero por años. Todos los sindicatos fueron intervenidos y los locales de los mismos fueron tomados por asalto por fuerzas militares apoyadas por comandos civiles. Para encabezar la Confederación General del Trabajo fue nombrado el capitán de navío Patrón Laplacette. El decreto más irritante para los peronistas, y que más nos interesa en el presente trabajo, fue el $\mathbf{4 1 6 1}$, mediante el cual se prohibió nombrar a Perón o Eva Perón en los medios de comunicación o en privado; también se prohibieron las marchas y los símbolos partidarios y se penó con reclusión a aquellos que tuvieran retratos, símbolos o hicieran pública su adhesión al gobierno peronista. En los medios de comunicación hicieron su apa. rición los eufemismos que designaban al gobierno de Perón como "el tirano depuesto", el "régimen depuesto", etcétera.

Sin embargo, el peronismo se reve.

4 No se tratan aquí los primeros sesenta días del gobiemo de Eduardo Lonardi cuya estrategia era diferente; véase Torre, Ejército, 1969. 
ló más persistente que lo que sus opositores suponían. Si en el terreno sindical el objetivo era modificar la relación de fuerzas existente en favor de los alia. dos de la "Revolución Libertadora", la creciente presión de los conflictos organizados por los peronistas puso un freno a sus aspiraciones: las jornadas perdidas por huelga aumentaron de 144120 en el año de 1955 a 516729.4 en 1956. Es interesante observar el carácter no sólo gremial sino también político que tienen la mayoría de los conflictos, dado que, en su mayor parte, eran realizados para lograr el reconocimiento de las estructuras informales como legítimas, mientras la remuneración media de los asalariados continuaba creciendo durante los tres años del gobierno de la "Revolución Libertadora". 5

Los decretos de anulación fueron acompañados de una efectiva represión a los militantes peronistas. En los primeros meses miles de dirigentes sindicales y políticos, delegados gremiales y simples militantes fueron encarcelados y torturados; a muchos de ellos se les aplicó la Ley de Residencia y a otros se los confinó durante un par de años en las cárceles del sur del país. En junio de 1956, un levantamiento militar organizado por cuadros del Ejército leales a Perón, fue duramente sofocado y los principales cabecillas fueron fusilados por sus camaradas de

5 Tomando como base 100 para 1960 , en 1955 fue de 110.1, en 1956117.1 y en 1957 113.7. El porcentaje de participación de sueldos y salarios en el PIB sufrió un leve descenso: 1955, 43.0; 1956, 42.6; 1957, 41.4. Datos de Rotondaro, Realidad, 1971. armas. Grupos de civiles que habían apoyado el golpe fueron sumariamente asesinados. ${ }^{6}$

La "Revolución Libertadora" se constituyó a sí misma otorgando significado a sus actos. El peronismo fue definido como un accidente de la vida democrática que había que superar, la adhesión de los trabajadores al régimen de Perón fue interpretada como posible por el uso de los recursos del Estado y la demagogia de Perón y su esposa. Cortados estos vínculos, eliminado el peronismo del uso de los recursos, prohibida su organización y denostados públicamente sus líderes, los sectores que habían dado su apoyo al régimen retornarían a la vida democrática civilizada que el nuevo gobierno encarnaba. Es por ello que tal revolución no aspiró a eternizarse en el poder y articuló, en el plazo de tres años, una nueva salida electoral. Su destino manifiesto era la eliminación del peronismo de la vida nacional.

Sin embargo, el peronismo no se diluyó en los partidos existentes y ello trajo consigo un debate entre los sectores que habían apoyado el golpe

6 Un grupo de civiles fue capturado en mo mentos previos a la asonada y llevados a un basural de la provincia de Buenos Aires, los obligaron a caminar por él para fusilarlos por la espalda; el número de muertos, entre civiles y militares fue de 26 hombres. Véase Ferla, Mártires, 1983 y Walsh, Operact6n, 1974.

7 En 1957 el gobierno de la "Revolución" convocó a elecciones para formar una Asamblea Constituyente que, entre sus fines, derogaría la Constitución Peronista de 1949. El objetivo no declarado era saber cómo reaccionarían los vo tantes peronistas en caso de proscripción. Perón ordenó el voto en blanco desde su exilio. El 
militar. ${ }^{7}$ El dilema del posperonismo rondó en torno al cómo desperonizar al país. Las opciones de "integraciôn" o "represión" marcaron los extremos de las alternativas posibles $y$, en torno a ellas, las principales fuerzas sociales y políticas se dividieron. Frente a esto, la acción del peronismo se alzó como una fuerza que, si bien no le permitía el retorno al poder, hizo, de todas maneras, inviable la hegemonía política de los sectores dominantes. ${ }^{8}$

\section{LA RESISTENCIA PERONISTA}

En 1955 los peronistas perdieron el control del Estado y el uso de los recursos provenientes de los aparatos sindicales; la dirigencia de primera línea político-sindical fue inhabilitada y encarcelada; el general Perón marchó al exilio y la represión se desencadenó en todos los ámbitos. Sin embargo, tres años después, en vísperas de las elecciones nacionales, la mayoría de los gremios industriales estaban nuevamente conducidos por peronistas y reclamaban la devolución de la Confederación General del Trabajo (CGT); poco menos de un año atrás -en 1957- habían demostrado

resultado fue que el peronismo no se había diluido en la proporción deseada: los votos en blan. co fueron mayoritarios, resaltando detrás las fracciones en que se había dividido el Partido Radical.

${ }^{8}$ El debate sobre el "empate hegemónico" en la Argentina posperonista sigue aún abierto. $\mathbf{P a}$ ra su análisis, véanse los siguientes trabajos: O'Donell, "Estado", 1977; Rouquie, "Hegemonía", 1982; Cavarozzi, Autoritarismo, 1983. que todavía poseían un gran caudal electoral; la resistencia, organizada en comandos clandestinos, se encontraba estructurada a nivel nacional e integraba a grupos de exiliados en los paí ses vecinos; frente a la salida electoral el peronismo había establecido un acuerdo con Arturo Frondizi que le garantizaba el acceso a la legalidad y el fortalecimiento de las organizaciones sindicales reconquistadas. Las predicciones de disolución del peronismo no se habían cumplido, por lo menos durante los años de la "Revolución Libertadora".

¿Cómo fue posible aquella rápida reconstrucción? ¿Se trataba del mismo peronismo existente hasta 1955 o era una nueva realidad, producto de la clandestinidad, la exclusión y la ilegalidad? ¿Cuáles fueron los valores viejos-nuevos que permitieron la reafirmación de la identidad colectiva? Aunque escape al objetivo de este trabajo hacer una descripción detallada de los primeros años de la resistencia es importante explicar sus características principales.

La resistencia peronista, o sea, el mantenimiento y crecimiento de la organización popular en las condiciones descritas, se basa, esencialmente, en dos estructuras interrelacionadas: los comandos clandestinos y las estructuras de base de los sindicatos.

\section{Los comandos clandestinos de la resistencia}

Incertidumbre, desazón, impotencia, son algunas de las palabras que pueden identificar el sentimiento de una 
gran parte de los trabajadores argentinos ante los hechos de $1955 . .^{9} \mathrm{Sin}$ embargo, el sentimiento de exclusión no condujo a todos a la misma salida. Para muchos no aparecía otra opción que la resistencia violenta. Según el testimonio de Juan Carlos Brid, citado por Daniel James:

No teníamos armas, no podíamos hablar ni votar, ni hacer nada. [...] No teníamos libertad de prensa alguna. Todo lo que teníamos era el decreto 4161 , el cual decía que aun si mencionábamos a Perón podíamos ir a la cárcel. No podíamos siquiera tener una foto de Perón en nuestras casas. Entonces recurrimos a los caños. ${ }^{10}$

Los comandos peronistas fueron pequeños grupos que surgieron desde las organizaciones de base existentes a lo largo y a lo ancho del país, en las zonas urbanas. Fueron organizados por dirigentes de segunda o tercera línea que habían escapado a la cárcel por no ser demasiado conocidos. Inicialmente eran una forma de reunión política, ${ }^{11}$ pero rápidamente los comandos más

\footnotetext{
9 El sentimiento de impotencia ha sido señalado acertadamente por James, Resistencta, 1990; en el transcurso de varias de mis entrevistas, el tema aparecía claramente relacionado con la pregunta acerca de lo que sucedió inmediatamente después del golpe militar. Entrevista del autor a delegados y obreros de fábrica, en Salas, Resistencia, CEAL, 1990.

10 Testimonio de Juan Carlos Brid, comando de la resistencia, cit, por James, Resistencia, 1990; el caño era un explosivo de reacción ácida de fabricación casera con un caño roscado en ambos extremos y lleno de nitroglicerina, lo que lo hacía muy inestable.

11 "Entrevista con Héctor Saavedra", comando de la resistencia, 25 julio 1988.
}

audaces pasaron a la acción: sabotajes a la producción, pintadas, atentados contra organismos del Estado, etc. La mayoría de las veces -en los orígenesno existía contacto entre los diferentes grupos ${ }^{12}$ y todos compartían una creciente desconfianza a integrarse bajo la autoridad de dirigentes que no hubieran surgido de ellos mismos. La misma reticencia evidenciaban frente a los dirigentes partidarios o frente a los antiguos funcionarios del gobierno. Desde muchos comandos se los acusaba de incapacidad para detener el golpe y los tildaban de dirigencia "adulona" $y$ "alcahueta". ${ }^{13}$ La legitimidad de los coman dos era dada por la incapacidad de la vieja dirigencia frente a las nuevas circunstancias. Los comandos peronistas de los primeros tiempos confiaban casi ciegamente en que un golpe de Estado, encabezado por los militares leales a Perón, restituyera rápidamente al gobierno peronista. Fue ésta una de las causas de que se movieran con audacia y con elementos mínimos de seguridad para la etapa clandestina en que se encontraban, y muchos de sus dirigen. tes cayeron en manos de los organismos de seguridad rápidamente. Una vez superado el intento golpista de Juan José Valle en junio de 1956, los grupos de comandos fueron estructurados en una organización mayor dirigida por el entonces delegado personal de Perón, John William Cooke. ${ }^{14}$

12 "Testimonio", 1963.

13 Véase el manifiesto del Comando Nacional Peronista de febrero de 1956 en Baschetti, Documentos, 1988.

14 Véase Perón-Cooke, Correspondencta, 1983. 


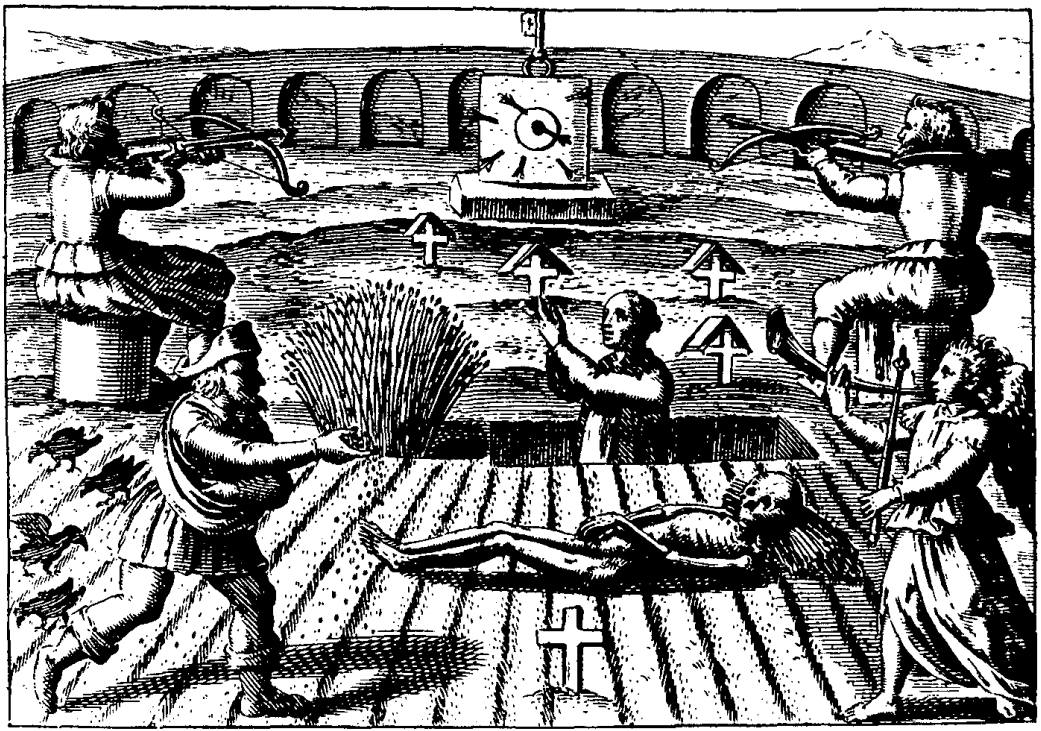

A pesar de que la actividad represiva descabezó a gran parte de los comandos, ${ }^{15}$ para 1957 muchos de ellos publicaban su propia prensa, comoel Comando Nacional Peronista que imprimía y distribuía el periódico El Guerrillero; también tenían acceso a "nuevos explosivos construidos en laboratorios que suplantaban el primitivo caño de reacción ácida". 16

Resulta dificil establecer con precisión el alcance de las acciones de los comandos peronistas. En primer lugar porque los medios de comunicación

15 "Testimonio", 1963; Vigo, Vida, 1973.

${ }^{16}$ El periódico El Guerrillero se imprimió en tabloide por más de un año. Acerca de la organización de laboratorios, véase Vigo, Vida, 1973 y Walsh, ¿Quién?, 1984. de la época no informan acerca de ellas salvo cuando un grupo es detenido. Generalmente, además, el grupo es identificado como un peligroso núcleo subversivo al que se le adjudican planes de envergadura contra el gobiemo y acciones pretéritas, las cuales, la mayor parte de las veces, debemos supo. ner que son falsas o magnificadas para justificar la adopción de medidas re. presivas. En segundo lugar, porque las acciones de los comandos de los primeros tiempos consistían en el re. parto de volantes, pintadas en los muros, sabotajes a la producción y atentados a los servicios públicos que no eran registrados por la prensa. Dado que la mayoría de los comandos estaban formados por obreros y conectados con las organizaciones sindicales clandesti- 
nas, el sabotaje industrial y los atentados en apoyo de las crecientes huelgas de 1956 y 1957 constituyeron las principales acciones de esta resistencia.

Las acciones violentas de los comandos fueron creciendo durante el periodo 1955-1959. En enero de 1959, durante el gobierno de Arturo Frondizi, y con motivo de una huelga general, los antentados sumaron más de un centenar en un sólo día.

Las estructuras de base sindicales: Comisiones Internas y Cuerpos de Delegados

Aunque la práctica de nombrar delegados que asumieran la representatividad de sus compañeros frente a la patronal en las fábricas y en los talleres ya existía desde los orígenes del movimiento obrero, el periodo peronista significó la efectiva consolidación de las Comisiones Internas y los Cuerpos de Delegados. Si bien este reconocimiento nunca estuvo incluido en una ley gremial, después de 1946, los contratos colectivos contemplarían tanto su aceptación como la estabilidad la. boral de los delegados. ${ }^{17} \mathrm{Al}$ no tener reglamentadas sus funciones en los convenios colectivos, de hecho, las Comisiones Internas asumieron una innumerable cantidad de funciones, entre ellas, el propio cumplimiento del convenio y su aplicación en el interior de los establecimientos. Según Daniel James " $[\ldots]$ a principios de los 50 ya habían asumido el papel más am.

17 Véase James, "Racionalización", 1981. plio de afianzar la seguridad de la clase obrera y limitar las prerrogativas de la patronal en la esfera productiva". ${ }^{18}$

Esta amplia gama de funciones sig. nificaban, en el ámbito mínimo de la vida obrera, la representación de una efectiva participación en el poder y una experiencia concreta que quedaría grabada en la conciencia de la clase trabajadora.

A partir de 1955, el derrumbe del Estado peronista fue acompañado por una efectiva intervención y represión sindical, como hemos señalado. Sin embargo y pese a ello, las comisiones in ternas, los cuerpos de delegados o las agrupaciones gremiales se reorganizaron como estructuras paralelas $e$ informales frente a aquellas que eran impuestas desde el poder. Durante el año de 1956, el elevado crecimiento de los conflictos fue debido, principalmente, a los intentos de reconocimiento que estas estructuras peronistas paralelas forzaron en las patronales y el Estado. Durante los dos primeros años, una nueva camada de dirigentes peronistas, ligados a las estructuras de la resistencia, fueron ganando posiciones y se alzaron con la mayoría de las conducciones de los gremios industriales del país. Cita Daniel James la siguiente queja:

Por octubre [de 1956] la Cámara de la Industria del Calzado se quejaba al Ministerio de Trabajo que "en la mayoría de las fábricas todos los puestos representativos han caído en manos de indudables adherentes al régimen depuesto cuyas actitudes estorban el normal desarrollo de las tareas en ellas".19

18 Ibid., p. 334.

19 Ibid. 


\section{RESISTENCIA Y CULTTURA POPUIAR}

I. He debido hacer todo este recorrido, aunque breve y un tanto esquemático, de las acciones de los sectores en pugna, para abordar una perspectiva diferente y complementaria de ellas: los valores culturales simbólicos que motivaban estas acciones populares y los significados que se construían históricamente sobre los actos de resistencia, y que modificaban o reafirmaban aspectos previos de la experiencia de la clase trabajadora.$^{20}$ En otras palabras, abor. dar aspectos de la cultura popular en su relación dinámica y contradictoria con la cultura de la clase dominante.

Aníbal Ford ha sido uno de los autores argentinos que recientemente ha revalorizado

[...] las formas de memoreo, recuerdo, transmisión familiar que se dan en los sec. tores populares y que constituyen uno de los canales internos por donde persiste la identidad política, en este caso la del peronismo, a pesar de las grandes y largas represiones

$y$, con ello, ha llamado a poner atención no sólo en la escucha de la oralidad popular, sino también a colocar en su justo lugar la "hipervaloración de lo escrito en el marco histórico y cultural de la constitución del Estado moderno $[\ldots]^{n}{ }^{21}$ En un sentido concordante se ha expresado James Petras. Intentando aclarar las causas de la rápida re.

20 Utilizo la categoria "experiencia de clase" entendida desde la definición de Thompson, Formación, 1978.

${ }^{21}$ Ford. Desde, 1987. constitución del movimiento de protesta en Argentina, luego del sangriento golpe militar de 1976 , aporta una serie de valiosas contribuciones para el conocimiento del obrar de la clase trabajadora y, entre ellas "[...] la permanencia de los lazos clasistas subyacentes, ubicados en la familia, la vecindad y la fábrica, reforzados por la cultura popular y provocados por la severa declinación del nivel de vida".22

La resistencia peronista resulta una etapa excepcional en la historia reciente de Argentina, pues en ella se han reafirmado, establecido y cristalizado una serie de aspectos importantes de la cultura popular y del imaginario colectivo.

En el artículo citado de Aníbal Ford, el autor hace hincapié en uno de los aspectos a ref lexionar en la cultura po. pular: el valor y el uso de los retratos. Llama la atención sobre el marco general de la iconografía elegida por los sec. tores populares, la costumbre difundida de fijar en retratos las imágenes de la vida familiar. En la microhistoria que analiza en su artículo aparece uno de los rasgos resistentes de la identidad política: los retratos de Perón y Eva Perón colocados en un lugar preponderante de los hogares humildes. Era ésta una constante, un hecho de reafirmación que se extendió en los primeros años de la resistencia. ${ }^{23}$

Juan Vigo, organizador de los primeros grupos clandestinos, lo comprobaba cotidianamente al asistir a reuniones en casas de delegados obreros que se organizaban como comandos:

22 Petras, "Terror", 1986.

${ }^{23}$ Ford, Desde, 1987. 
La señora dejó su plancha pese a mis protestas, pues yo había sido el primero en llegar y la reunión aún demoraría [...] sobre la pared abundaban las fotografias de Evita y el general Perón. Con orgullo tan grande, como legítimo, me señaló una de las fotos donde se hallaba Evita entre varias mujeres $[. ..]{ }^{24}$

Similäres relatos aparecen relacionados con el efecto antagónico que produjo la sanción del decreto 4161 al que hemos aludido. Nombrar a Perón o Eva Perón podía ser penado con prisión, tener retratos de ambos en las casas tenía el mismo resultado. Los primeros hechos de la resistencia, entonces, fueron, precisamente, nombrarlos públicamente.

Un hecho que demuestra la eficacia simbólica de los retratos como forma de resistencia me fue relatado por Héctor Saavedra, comando de la resistencia y obrero del Frigorífico Municipal de Buenos Aires. Ocurrió poco tiempo después del golpe de Estado, el frigorífico se encontraba rodeado de fuerzas militares, aun cuando sus tareas se desarrollaban normalmente:

[...] tenemos que hacer algo. Eran las once. Yo entraba a las doce pero había estado en el turno de la mañana y había ido al café. [...] adentro [en el patio del frigorífico] había un busto de San Martín y uno de Evita que no se habían animado a sacarlo. El 26 de septiembre, con Lonardi en el poder no se habian animado a sacar el busto del frigorífico. Y se me ocurre, epor qué no le colocamos una palma en el busto de Evita? [...] Los muchachos que estaban en el café que eran varios, ya habian entrado al frigorífico a

${ }^{24}$ Vigo, Vida, 1973, p. 130. avisar. El frigorífico estaba trabajando a esa hora, estaba todo ocupado, estaba la faena. Yo iba con la palma. El asunto era cuando llegara donde estaba el Ejército. Cuando me acerqué, los soldados y los suboficiales me decian: " $B$ Bien pibe! ¡Bien pibe!" Entonces yo tomé más coraje y llegué a la vigilancia. Con ellos no pasaba nada, eran conocidos [...] Me vieron entrar con la palma y estaba todo el mundo asomado desde los cuatro pisos para ver... ya estaba el ambiente. Cuando vieron que pasé el busto de San Martín y vieron que doblé, ya se me habían acoplado dos o tres que eran los que estaban adentro. ¡Y se venía abajo! Empezaron a gritar: ¡Peeerón, Peeeerón!25

Eva Perón, en particular, sería elevada a la categoría de mito popular. Durante su corta vida fogosa y temperamental su labor fue ser el vínculo entre Perón y los trabajadores mediante su trabajo en la CGT. EI mito Evita, sin embargo, fue creado e impulsado desde el propio gobierno peronista. A su muerte, un equipo médico encabezado por el doctor Pedro Ara comenzó las tareas de embalsamiento encargadas por Perón. A la espera del monumento en donde sería depositado, el cadáver embalsamado fue colocado en la sede de la central obrera bajo una cúpula de cristal donde era visitada por el público.

Durante muchos años, los mecanismos de propaganda del gobierno peronista, legisladores, políticos, sindicalistas y las revistas adictas, habían ensalzado su figura como un ser movido solamente por el amor. Era la Primera Samaritana, el Consuelo de los Humildes, la Jefa Espiri1988.

25 "Entrevista con Héctor Saavedra", 25 junio 
tual de la Nación, alabada y loada hasta alturas siderales en los meses previos a su muerte. ${ }^{26}$

Frente a ello, la "Revolución Libertadora ${ }^{n}$ intentaba conmover las bases de la adhesión popular con la prohibición del adversario, al mismo tiempo que una intensa campaña de prensa intentaba "demostrar a los partidarios de Perón que habían vivido ciegos y engañados durante diez años". ${ }^{27}$

Pero Evita no era sólo propaganda peronista. Cuando las fotografias fueron destruidas, las estatuas derribadas, el cadáver secuestrado y sus libros quemados, se convirtió en símbolo de resistencia. Cada recordatorio de su muerte

[...] mientras otras fechas pasaban desa. percibidas $[. .$.$] se fueron convirtiendo en$ batallas campales. Las misas en su memo. ria eran actos de militancia durante los cuales los partidarios de Perón inevitable. mente se enfrentaban con la policía. ${ }^{28}$

La religiosidad popular transmutó a la Evita símbolo en la Evita Santa y su imagen fue adorada en privado mediante altares y velas encendidas en los hogares humildes.

II. El 23 de septiembre de 1955 el general Eduardo Lonardi prestó juramento como presidente provisional. En la plaza de Mayo se había congregado una multitud para saludarlo y expresar su apoyo al golpe contra Perón. Ese día los vendedores ambulantes ofrecían en venta unos banderines en cuyo fondo

${ }^{26}$ Navarro, Eutta, 1981 , p. 326.

27 Ibtd., p. 319.

28 Ibid., p. 333. estaban impresas la bandera argentina y la bandera papal, y sobre las cuales se veía una letra " $V$ " con una cruz encima de ella, más abajo la fecha del golpe: " 16 de septiembre de 1955". El simbolismo de la unidad de la Iglesia católica y las Fuerzas Armadas en el golpe salta a la vista. La "V" más la cruz encima de ella significaban "Cristo Vence".

Tiempo después los peronistas resignificaron el símbolo, cambiando el centro mismo del sentido que le había atribuido la "Revolución Libertadora". Manteniendo la " $\mathrm{V}$ " original, la cruz fue cambiada por una " $P$ " con el sentido de "Perón Vuelve". Pintada en las paredes como la expresión más sintética del movimiento, la VP se transformó en el símbolo por excelencia de la resistencia por más de veinte años.

III. El humorista Délfor, creador del famoso programa radial "La Revista Dislocada", había montado, en el verano de 1955, un espectáculo en la calle Corrientes con el nombre de "Marabunta", en el que se hacía una parodia de películas famosas. En la parte culminante del espectáculo, al personaje del científico, que conduce una expedición en busca de un cementerio de gorilas y que siempre está alcoholizado, le preguntan: “Escuchaste?, ¿qué será ese ruido?", y él contestaba: "Deben ser los gorilas, deben ser". El éxito que tuvo la frase hizo que Délfor la incluyera en su programa radial. Al mes sacaron un disco con el tema "Deben ser los gorilas". Se vendieron 55000 ejemplares inmediatamente. Después del golpe y dado que todos los sufrimientos de los trabajadores eran atribuidos a la "Revolución Libertadora", 
cada vez que se hablaba del gobierno y sus males, se popularizó el decir: "Deben ser los gorilas, deben ser", fusionando asi "gorilas" y gobierno. ${ }^{29} \mathrm{~A}$ partir de allí, el término pasó a designar al antiperonismo sin distinción de ideologías o sectores, pero particularmente a los sectores de las Fuerzas Armadas y a los partidos políticos que eran furiosamente antiperonistas. Años después también pasó a significar reaccionario y con este sentido se extendió por América Latina. En los primeros tiempos de la resistencia sirvió como reafirmación por oposición. El peronismo se constituía a sí mismo en la construcción de su opuesto.

IV. Muchos de estos valores se encuentran con fuerza en los relatos de la organización de los primeros grupos juveniles en 1957:

[...] Nosotros empezamos el activismo allá por el 57 en la esquina de Corrientes y Esmeralda, un lugar que fue símbolo de la resistencia peronista. Allí nos juntábamos con gente en forma espontánea a cantar la "marchita" o simplemente a silbarla, y como en ese momento estaba vigente el decreto 4161 que proscribía al peronismo y su simbología, enseguida caía un carro de asalto de la policía y nos hacía circular. Cuando nos resistíamos nos dispersaban a palo limpio. Otras veces poníamos una foto de Perón y una de Evita colgando del cartelito en el que estaba el número de la calle, y nunca faltaba un "gorilón" que caía en el lugar y la intentaba sacar. $Y$ por supuesto, cobraba de lo lindo... [...] Así nos fuimos conociendo con otros

29 "Deben ser los gorilas, deben ser" en revista Crisis, núm. 63, agosto 1988. compañeros con los que formaríamos la Juventud Peronista. 30

Desde el principio, el hecho más simple de la resistencia era cantar la "Marcha Peronista" en los estadios de futbol. Pero no eran los únicos:

[A mi casa] la llamaron siempre "El Fortín". Yo en 1955 puse parlantes en el techo. Hasta el 55, sólo tuve dos retratos chicos, chiquitos de Perón y de Evita. [...] Puse los parlantes en el techo y la montada se paraba a una cuadra y no se animaba a llegar. 31

Los mismos hechos, desde una perspectiva similar, me relató Norberto Capdevielle, delegado del frigorífico Lisandro de la Torre:

El peronista se sentía tocado y le causaba escozor que otro no sea peronista. Hubo un momento en que no se podía nombrar a Perón. Usted iba preso nombrando a Perón. Cantar la marcha peronista la cantábamos en las canchas, $y$ venía la policía a palos. Y seguíamos cantando la marcha. Porque a un hombre no se le puede sacar a palos la idea. [...] Usted en un hombre va a manejar todo el cuerpo, pero la mente no la va a manejar. Usted le está pegando y no sabe si lo está insultando, lo está maldiciendo. La mente no se maneja. Y no la van a manejar jamás. 32

30 Reportaje a Envar El Khadre, en revista Caras y Caretas, núm. 2209, abril 1984.

31 Testimonio de Helena Viale, en "Testimonios de la Resistencia Peronistan, Militancia, núm. 2, 21 junio 1973.

32 Entrevista con Norberto Capdevielle, 14 mayo 1988. 
Muchas veces, momentos previos a la represión de una movilización, los manifestantes entonaban las estrofas del himno nacional y obligaban a las fuerzas represivas a actuar en contra de "lo nacional". La propia canción a la patria era usada como herramienta de resistencia.

\section{CONCLUISIONES}

¿Una creación popular autónoma, independiente de los significantes de la cultura dominante, o una creación a partir de la argamasa contradictoria de mensajes y significados a la que se aplica la experiencia histórica, la del memoreo y las prácticas cotidianas que surgen de la lucha? Más bien esto último parecen ser los valores del peronismo en la resistencia.

De aquella maraña tratamos de sacar algunas conclusiones necesarias. Una paradoja no siempre comprendida parece envolver al peronismo. No podría decirse que Perón haya construido un gobierno puramente obrero, en el sentido lato de la palabra, ni tampoco un partido de clase, sino que más bien estimuló permanentemente la concordancia, la conciliación entre las clases sociales. Se ha discutido incluso el papel que la clase obrera tuvo en la estrategia peronista, llegando muchos autores a la conclusión de que permaneció como clase subordinada a una estrategia burguesa de industrialización. Sin embargo, la identidad resistente del peronismo y el recuerdo colectivo tendieron a gestar el mayor enfrentamiento clasista de la Argentina moderna; aun incluido den- tro del marco del sistema, el movimiento tendió permanentemente a salirse de él. Un imaginario colectivo plagado de tradicionalismo pero inconciliable por los reclamos obreros, se convirtió históricamente en un movimiento dinámico y contradictorio que se opuso efectivamente a la hegemonía de la clase dominante y que gestó en su seno contradicciones insolubles que estallarian tiempo después.

Algunos de los valores expresados de la cultura popular permiten sacar otras conclusiones, aparte de la expuesta. En primer lugar, una tendencia a la unidad del movimiento, no tanto expresada en el reconocimiento de la mismidad, de la autorreferencia - basada en acciones iguales y en la misma cosmovisión-, sino por oposición dentro del campo del peronismo-antiperonismo. La descripción a la que alude el término "gorila" no sólo identifica de manera general al adversario, sino que unifica también todo lo "no gorila", aun cuando se trate de "duros" o "blandos", "combativos" o "colaboracionistas". De ello también que, la única autoridad para establecer el "adentro" o el "afuera", residiera cada vez más en la figura de Perón.

Las nuevas condiciones del enfrentamiento clasista refuerzan las experiencias vividas históricamente por la clase obrera, como hemos visto, por la revalorización de las estructuras de base como el sitio donde se articula la búsqueda de poder. Pero podríamos añadir también el lugar de división entre aquellos que buscan la alianza con el Estado para sus acciones políticas y 
aquellos que utilizan los sindicatos con un sentido político más vasto. ${ }^{33}$

Atrás de todo ello, la unidad se funda en el reconocimiento común de la mayoría de los trabajadores de un pasado mejor, el cual se transfiere al presente como bandera del futuro. La construcción de símbolos de resisten. cia, como el de "Perón Vuelve", deben ser vistos desde esta perspectiva. No es sólo Perón el que tornará de su exilio a partir de las acciones de la resistencia, sino el pasado peronista, aun cuando éste ya será imposible de reconstruir.

La "Revolución Libertadora", con sus decretos anulatorios, se constituía a sí misma culturalmente a partir de la exclusión del peronismo. La propaganda contraria al "régimen depuesto" aparecería como sentimiento de exclusión en los escritores peronistas. Así, años después, Leopoldo Marechal, en su novela Megafón o la guerra expresaba este sentimiento:

Desde fines de 1955 -les dije-, con un pueblo en derrota y su líder ausente, soy un desterrado corporal e intelectual. Y añadi: En nuestra fauna sumergida existen hoy el Gobernante Depuesto, el Militar Depuesto, el Cura Depuesto, el Profesor Depuesto y el Cirujano Depuesto. No quedó aquí ningún hijo de madre sin deponer. 34

Este sentido de la exclusión admitió, sin embargo, muchas respuestas, desde la impotencia pasiva, pasando por la acción sindical en las fábricas,

33 Véase esta tradición del movimiento obrero en Del Campo, Sindicalismo, 1983.

34 Marechal, Megafon, 1970. hasta las acciones violentas de la resistencia. Pero su unidad y sentido estaban dados por aspectos a la vez simbólicos y reales construidos en común.

¿Cuáles fueron las formas, las vías por las que esta construcción fue realizada? Con los medios de comunicación en manos de los vencedores de 1955 y con una campaña de prensa adversa al peronismo, a pesar de la represión, a pesar de los locales políticos y sindicales cerrados, el sentido de la resistencia fue trasmitido por años en. tre los sectores populares, $y$ de generación en generación.

Eliminadas las fuentes formales de la organización comenzaron a jugar un papel preponderante las organizaciones informales, los ámbitos mínimos de la vida cotidiana, mucho más permeables a la represión. Según James Petras

las vecindades y los lugares de trabajo son en Argentina predominantemente homogéneos en términos de clase, por lo menos hasta el punto de contener principalmente obreros y empleados de sueldo bajo y pequeños vendedores $[\ldots]$ por lo menos dos generaciones (1940. 1950 y 1960-1970) compartieron experiencias comunes de lucha y organización clasista. 35

A pesar de que estas afirmaciones deban ser revisadas para el presente, ${ }^{36}$

35 Petras, "Terror", 1986, p. 292.

36 Por los efectos de la desintegración de la clase obrera, producidos por el régimen militar iniciado en 1976 y cuyas consecuencias fueron mucho más visibles a partir de 1983: emigración, éxodo de pobladores más allá de la periferia de la ciudad de Buenos Aires, nuevos asentamientos, etcétera. 
en mi investigación sobre las luchas del frigorífico municipal de Buenos Aires y del barrio de Mataderos he llegado a las mismas conclusiones.

Estos ámbitos mínimos de la vida del pueblo son: $a$ ) las fábricas y, en ellas, las comisiones internas, los cuerpos de delegados y, en algunos casos, los sindicatos de fábrica; ${ }^{37}$ y $b$ ) los barrios y, en ellos, los clubes de futbol, las organizaciones vecinales, los lugares de esparcimiento y las propias casas de familia.

En cuanto a las comisiones internas y los cuerpos de delegados, ya hemos destacado la importancia que habian adquirido en la experiencia de los obreros. Cuando fueron intervenidos siguieron funcionando como estructuras paralelas que ejercian un efectivo control de los establecimientos: la mayoría de las huelgas de esos años fueron organizadas por estas estructuras. Su fuerza residía no sólo en su capacidad de orga. nizar a los afiliados, sino también en la necesidad de las patronales de contar con interlocutores reales con vistas a ordenar la producción.

La mayoría de los barrios de la ciu. dad de Buenos Aires tenían una activa vida social. Cierta prosperidad conseguida por los trabajadores durante los gobiernos peronistas y mantenida por algunos años, les permitía la asistencia a lugares de diversión cuyo centro era ocupado por los clubes barriales. En cada localidad existía un "centro", normalmente una arteria con negocios co-

37 Los sindicatos de fábrica no eran muy comunes en el periodo estudiado. Un ejemplo de todas maneras, lo constituye la organización del frigorífico estatal. merciales, cafés, restaurantes, a los que concurrían -sobre todo los fines de semana- los obreros y empleados del barrio. El conocimiento entre vecinos era mutuo y familiar.

Los estadios de futbol fueron convertidos, por los núcleos organizados de la resistencia, en lugares de expresión colectiva y, por extensión, en vías de comunicación no formal. El testimonio más común en entrevistas y testimonios era que se captaban militantes cantando la marcha peronista en los mismos.

Las casas de familia, los clubes, los cafés y los lugares habituales de reunión eran canales naturales de expresión y, por su cotidianidad, se convertían en lugares seguros contra la represión. Incluso hay testimonios de reuniones de los comandos en los medios de transporte. 38

En cuanto a la propaganda escrita, ocupó un lugar que fue creciendo progresivamente. En los primeros tiempos, las directrices de Perón, enviadas desde el exilio a los comandos, se transmitían oralmente o eran mecanografiadas en cadena. Ya para 1957 existía una prensa clandestina y semiclan. destina bastante organizada.

Por último, la cárcel se convirtió, paradójicamente, en el lugar donde se comunicaban los distintos grupos de la resistencia. Según los testimonios, muchos de los delegados obreros fueron captados en los lugares de detención. Para muestra bastará el siguiente relato:

38 El comando L1 13 se llamaba así porque sus reuniones se hacían en un ómnibus de esa línea, cerraban las puertas y hacía su recorrido habitual. "Testimonio", 1963. 
en la cárcel las celdas de incomunica. ción son pequeñas, largas y estrechas. Tienen una ventanita con barrotes muy arriba de la cama. Había detenido un comunista que se llamaba Manso. Se subía sobre el respaldo de la cama. Y a los gritos nos pedía el nombre y el número de celda de todos. No lo podian hacer callar. Cuando lo obligaban, el bolche gritaba "iViva Perón, carajo!" Él no estaba incomunicado, le permitían ver a la señora que tenía un bebé de dos meses. En la bombachita de goma del bebé metía la lista de los detenidos y la señora la llevaba a la Liga por los Detechos del Hombre. [...] Cuando nos ponían en libertad los peronistas salíamos cantando la marcha. 39

No obstante, lo anterior no nos lleva a pensar que todos participaban de la misma manera de los significados, ni que los mensajes de la cultura dominante resultaran inocuos en el conjunto de los sectores populares. Lo que se afirma aquí es que no todos participaron en la resistencia pero, a pesar de ello, la resistencia involucró a todos los sectores populares de una u otra manera. Una de esas maneras fue la memoria, y la forma de preservarla convertía a muchos en resistentes sin saberlo. Podían no estar de acuerdo con que se realizaran hechos de violencia, pero no se cuestionaban su propia violencia en una movilización callejera. Muchos eran simples oficinistas u obreros que no pensarían en participar en acciones de sabotaje, pero que sí cantaban la marcha en los estadios o tenían en sus casas fotos de Perón o Eva Perón. La mayoría no guardaba armas o explosivos en su casa ni era si-

39 Ibid. quiera "correo" (mensajero) de los comandos de la resistencia, pero usaba los significados de las palabras "inventadas" en el mismo sentido que éstos. Si bien no participaban de reuniones sindicales, tampoco las denunciaban a los medios de seguridad si se enteraban de ellas. Y por encima de todo, había aquella mirada hacia atrás, a los días de apogeo de los derechos laborales y de los beneficios sociales que constituían su experiencia de dignidad de clase, y que, elevada a la categoría de mito del pasado, pretendían volver a recuperar.

Veinticinco años después, una nueva generación de militantes enfrentó un sangriento golpe militar. Muchos de estos militantes basaron sus acciones en la experiencia de la resistencia peronista y adecuaron sus métodos de lucha según aquellos referentes de clandestinidad que les habían sido transmitidos oralmente. ${ }^{40}$

\section{BIBLIOGRAFIA}

-Bascheetti, Roberto, Documentos de la Resistencia Peronista, 1955-1970, Puntosur, Buenos Aires, 1988.

-Cavarozzi, Marcelo, Autoritarismo y democracia (1955-1983), CEAL, Buenos Aires, 1983.

-Del Campo, Hugo, Sindicalismo y Peronismo, Clacso, Buenos Aires, 1983.

-Ferla, Salvador, Mártires y verdugos, Peña Lillo, Buenos Aires, 1983.

-Ford, Aníbal, Desde la orilla de la ciencia. Acotaciones sobre identidad, in. formacióny proyecto cultural en una etapa de crisis, Puntosur, Buenos Aires, 1987.

40 Véase Pozzi, Oposictón, 1988. 
-García Canclini, Néstor, Ideología y cultura, Buenos Aires, Secretaría de Bienestar Estudiantil, 1988.

-Hall, Stuart, "Notas sobre la desconstrucción de lo popular", en Raphael Samuel (comp.), Historia popular y teoría socialista, Crítica, Barcelona, 1984.

-James, Daniel, "Racionalización y respuesta de la clase obrera: contexto y limitaciones de la actividad gremial en Argentina", Desarrollo Económico, vol. 21, núm. 83, octubre-diciembre 1981.

-James, Daniel, Resistencia e integración: la clase trabajadora y el peronismo, Sudamericana, Buenos Aires, 1990.

-Marechal, Leopoldo, Megafón o la guerra, Sudamericana, Buenos Aires, 1970.

-Navarro, Marysa, Evita, Corregidor, Buenos Aires, 1981.

-O'Donell, Guillermo, "Estado y alianzas en la Argentina, 1956-1976", Desarrollo Económico, vol. 16, enero-marzo 1977.

-Perón-Cooke, Correspondencia, Parlamento Buenos Aires, 1983.

-Petras, James, "El terror y la hidra: el resurgimiento de la clase trabajadora argentina" en James Petras (comp.), Clase, Estadoy poder en el Tercer Mundo, Fondo de Cultura Económica, México, 1986.

-Pozzi, Pablo, Oposición obnera a la dictadura, Contrapunto, Buenos A ires, 1988.
-Rotondaro, Rubén, Realidad y cambio en el sindicalismo argentino, Pleamar, Buenos Aires, 1971.

-Rouquie, Alain, "Hegemonía militar, Estado y dominación social", en A. Rouquie (comp.), Argentina hoy, Siglo XXI, México, 1982.

-Salas, Ernesto, La Resistencia Peronista, la toma del frigorifico Lisandro de la Torre, CEAL, Buenos Aires, 1990.

-Testimonio del "compañero Fermín", comando de la resistencia en el Gran Buenos Aires, en "Testimonios de la Resistencia Peronista", Militancia, núm. 3, 28 junio 1963.

-Thompson, E. P., La formación de la clase obrera en Inglaterra, Laia, Barcelona, 1978.

-Torre, Juan Carlos y Santiago Senen González, Ejército y sindicatos, los sesenta días de Lonardi, Galerna, Buenos Aires, 1969.

-Vigo, Juan M., jLa vida por Perbn! Crónicas de la resistencia, Peña Lillo, Buenos Aires, 1973.

-Walsh, Rodolfo, Operación masacre, De la Flor, Buenos Aires, 1974.

- ¿Qutén mató a Rosendo?, De la Flor, Buenos Aires, 1984. 


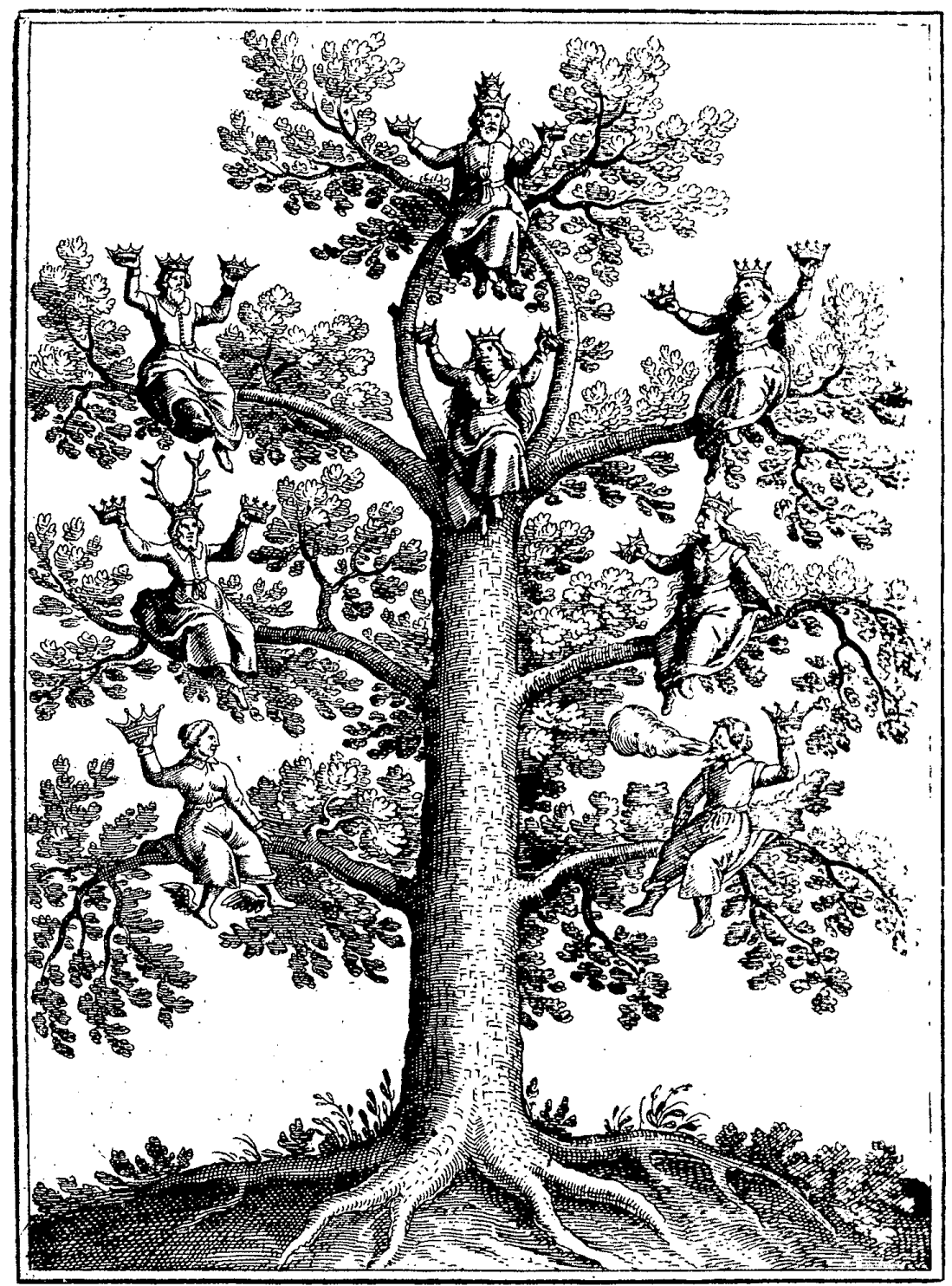

